Socioeconomic Institute

Sozialökonomisches Institut

Working Paper No. 0303

\title{
Mobile Number Portability
}

Stefan Buehler and Justus Haucap

March 2003 
Socioeconomic Institute

University of Zurich

Working Paper №. 0303

Mobile Number Portability

March 2003

Author's addresses Stefan Buehler

Sozialökonomisches Institut

Universität Zürich

Hottingerstrasse 10

$\mathrm{CH}-8032$ Zürich

Phone: +41-1-634 0606

E-mail: sbuehler@soi.unizh.ch

Justus Haucap

University of the Federal Armed Forces Hamburg

Institute for Economic Policy

Holstenhofweg 85

D-22043 Hamburg, Germany

E-mail: justus.haucap@unibw-hamburg.de.

Publisher

Sozialökonomisches Institut

Bibliothek (Working Paper)

Rämistrasse 71

CH-8006 Zürich

Phone: +41-1-634 2137

Fax: +41-1-634 4982

URL: www.soi.unizh.ch

E-mail: soilib@soi.unizh.ch 


\title{
Mobile Number Portability*
}

\author{
Stefan Buehler ${ }^{\dagger}$ \\ University of Zurich and University of St. Gallen \\ Justus Haucap $\ddagger$ \\ University of the Federal Armed Forces Hamburg
}

July 2003

\begin{abstract}
This paper examines the consequences of introducing mobile number portability (MNP). As MNP allows consumers to keep their telephone number when switching providers, it reduces consumers' switching costs. However, MNP may also cause consumer ignorance if telephone numbers no longer identify networks. As a result, while fostering competition for mobile customers, MNP may also induce operators to increase termination charges for calls to mobile networks, generating ambiguous welfare effects. We examine how extensions such as MNP based on call-forwarding, termination fee regulation, and alternative means of carrier identification affect these findings.

Keywords: number portability, switching costs, telecommunications, network competition

JEL Classification: L13, L51, L96.

\footnotetext{
*This article was much improved by the comments of an anonymous referee and the editor of this journal, Donald Lamberton. We also thank Daniel Halbheer, Warwick Izzard, Christian Koboldt, Jörn Kruse, Armin Schmutzler, Tommaso Valetti and participants at the 3rd ZEW Conference on the Economics of Information and Communication Technologies at Mannheim for their helpful comments and discussions. Of course, the usual disclaimer applies.

${ }^{\dagger}$ University of Zurich, Socioeconomic Institute, Hottingerstr. 10, CH-8032 Zurich, Switzerland; email: sbuehler@soi.unizh.ch.

$\ddagger$ University of the Federal Armed Forces Hamburg, Institute for Economic Policy, Holstenhofweg 85, D-22043 Hamburg, Germany; e-mail: justus.haucap@unibw-hamburg.de.
} 


\section{Introduction}

Mobile number portability (MNP) requires that mobile telephone customers can keep their telephone number - including the prefix - when switching from one provider of mobile telecommunications services to another. In the absence of MNP, customers have to give up their number and must adopt a new one when they switch operators. As a result, customers face switching costs associated with informing people about changing their number, printing new business cards, missing valuable calls from people that do not have the new number, etc. Based on these considerations, many regulatory authorities have imposed mandatory $\mathrm{MNP}$ - or are about to require its introduction - so as to reduce customers' switching costs, attempting to make mobile telecommunications more competitive (see, e.g., Reinke, 1998).

The world's first country to introduce MNP was Singapore in 1997, followed by the UK, Hong Kong and the Netherlands in 1999. As of 2003, a number of other countries, especially in Europe, require MNP (see Table 1).

Table 1: Introduction of MNP in Selected Countries

\begin{tabular}{cc}
\hline \hline Year & Countries where MNP is available \\
\hline 1997 & Singapore \\
1999 & UK, Hong Kong, Netherlands \\
2000 & Spain, Switzerland \\
2001 & Australia, Sweden, Denmark, Norway \\
2002 & Belgium, Italy, Portugal, Germany \\
2003 & Ireland, France, Finland \\
2004 & Luxembourg, Greece (planned), Austria (planned) \\
not clear & Canada, New Zealand, Japan, South Korea, Taiwan, Mexico \\
\hline
\end{tabular}

Sources: European Commission (2002), INTUG (2003); own research

The rationale of introducing MNP is simple: MNP is expected to bring about considerable benefits to users of mobile telephony services (see, e.g., Oftel, 1997; NERA/Smith, 1998;. Ovum, 2000; AAS/LECG, 2001). Adopting the classification originally proposed by NERA when it considered the case of introducing number portability for fixed line services in the UK in the mid 1990s, Table 2 lists four types of consumer benefits that have been examined as part of the various cost-benefit-analyses conducted for advising regulatory authorities' on MNP.

Much of the analysis has focused on type 1 and type 2 benefits, since type 3 benefits are usually considered to be relatively small (see, e.g., Oftel, 1997; Ovum, 2000; Schwarz- 
Table 2: Benefits of MNP

\begin{tabular}{|c|c|c|}
\hline Type of Benefit & Applies to & Benefit \\
\hline $1 \mathrm{~A}$ & $\begin{array}{l}\text { Users who switch } \\
\text { even without MNP }\end{array}$ & $\begin{array}{l}\text { Avoided costs of number change } \\
\text { (e.g. informing users, lost calls) }\end{array}$ \\
\hline $1 \mathrm{~B}$ & $\begin{array}{l}\text { Users who only } \\
\text { switch with MNP }\end{array}$ & Benefits of moving to a new operator \\
\hline 2 & All users & Benefits of stimulating competition \\
\hline 3 & Callers & Avoided costs of finding changed numbers \\
\hline
\end{tabular}

Source: Oftel (1997, p.4), Ovum (2000, p.7)

Schilling and Stumpf, 1999). In the academic literature, type 2 benefits have received special attention. The intuitive notion that number portability enhances competition due to reduced switching costs has formally been analyzed by Aoki and Small (1999), who examine the welfare effects of MNP for different levels of mobile penetration (or market saturation). They find that the overall welfare effect of MNP is ambiguous if the investment costs of implementing a MNP system are weighed against the benefits of more intense competition between mobile operators. In related papers, Gans, King and Woodbridge (2001) and Haucap (2003) have focused on the question of how to allocate the property rights in telephone numbers and the costs of implementing number portability.

An important aspect that has largely been ignored in this debate is the fact that MNP can make it more difficult for consumers to distinguish between different networks when placing a call. In the absence of MNP, consumers can usually distinguish between different mobile networks through the number prefix. ${ }^{1}$ When MNP is introduced, however, the number prefix does not automatically indicate the network assignment of a given number. As a result, if calling prices differ between different networks, consumers may be unaware of exact charges for placing calls to mobile networks. As Ovum (2000, p.8) acknowledges in its cost-benefit-analysis of MNP in Ireland,

"the first three digits of the called number no longer indicates the network operator of the called subscriber reliably. Full tariff transparency is therefore

\footnotetext{
${ }^{1}$ For example, in New Zealand all Vodafone numbers start with the prefix 021 while Telecom New Zealand uses the 025 numbering range. Similarly, in Ireland Meteor allocates seven digit subscriber numbers from behind the code 085, Digifone allocates subscriber numbers from behind the code 086 and Eircell allocates subscriber numbers from behind the code 087. In Austria, tele.ring's numbering range starts with 0650, while Mobilkom uses 0664, T-Mobile 0676 and Connect/One 0699. In Switzerland, Swisscom uses the prefix 079, whereas Orange and Sunrise use the 078 and 076 numbering ranges, respectively.
} 
lost and, unless prices change, callers end up paying a lot more than expected for certain calls."

The effects of consumer ignorance with respect to relevant prices have recently been explored by Gans and King (2000) and Wright (2002). They show that mobile operators may have incentives to increase their termination charges if consumers only take notice of average retail prices. Furthermore, they suggest that MNP may deteriorate the customers' price information. However, they do not formally work out the argument or analyze the trade offs associated with the introduction of MNP.

The present paper aims to fill this gap by analyzing the potential trade off between more intense competition and (increased) consumer ignorance associated with MNP. To that end, we assume that the introduction of MNP eliminates switching costs (A1), and deteriorates the customers' information about the relevant prices (A2). Allowing for more subtle price effects of MNP than previous studies, ${ }^{2}$ we find that the welfare effects of introducing mandatory MNP are generally ambiguous if (A1) and (A2) are satisfied. ${ }^{3}$ More specifically, we show that, in this case, the introduction of mandatory MNP is less likely to generate welfare gains (i) the closer substitutes mobile networks are, and (ii) the larger the market for fixed line telephony.

The intuition of these results is straightforward: If mobile networks are close substitutes and competition is thus intense, introducing MNP does not strongly affect the consumers' subscription decisions. That is, the benefits of introducing MNP are small. However, the costs of introducing MNP persist if consumers are unaware of specific termination charges and thus base their calling decisions on average prices. This induces mobile operators to increase their termination charges, thereby adversely affecting the fixed line telephony customers. The latter effect is more pronounced if the market for fixed line telephony is large.

Having identified why the introduction of MNP may generate adverse welfare effects, we examine a number of extensions to our analysis. First, we analyze how our results are affected if MNP is implemented using "call-forwarding" rather than an "Intelligent Network" (IN) solution, where call-forwarding typically features higher marginal costs (due to inefficient rerouting) but lower fixed costs than the IN technology. We find that due to higher termination charges, both fixed line and mobile customers are worse

\footnotetext{
${ }^{2}$ Some of these studies simply assumed that MNP will generate a drop in mobile prices across the board (see, e.g., Ovum, 2000, p.7, or Schwarz-Schilling and Stumpf, 1999).

${ }^{3}$ In contrast, if consumers are ignorant irrespective of MNP or if a jurisdiction does not have mobile prefixes (as, e.g., in the US), introducing MNP has no effect on the transparency of mobile tariffs. The trade off underlying our analysis then becomes trivial in the sense that introducing mandatory MNP unambiguously generates positive welfare effects.
} 
off with call-forwarding. However, since investment costs are typically lower with callforwarding, the welfare comparison with the IN solution is ambiguous.

Second, we show that with regulated termination charges, the case for introducing MNP becomes much stronger. This follows from the fact that under this type of regulation, introducing MNP is unlikely to increase termination charges. Therefore, both fixed line and mobile customers are (weakly) better off, and introducing MNP is thus welfare improving if investment costs are not prohibitive.

Finally, we consider the case where MNP is supplemented by alternative means to identify networks (such as an acoustic signal or toll-free enquiry numbers). We find that such alternative means help generating positive welfare effects if the costs of implementing them are not too high (and the nuisance to customers is small).

The remainder of the paper is organized as follows. In Section 2 we introduce the analytical framework and present the key results of our analysis. In Section 3, we examine a number of extensions outlined above. Finally, section 4 discusses policy implications and concludes.

\section{The Model}

There are two mobile networks $i=A, B$ and a fixed line telephony market of size $k>0$. We assume that fixed and mobile telephony constitute two different markets, so that there is no intermodal competition between fixed and mobile operators. The mobile networks are assumed to be differentiated along a Hotelling line of length 1 with network $A$ being located at 0 and network $B$ at 1 . Suppose that $A$ is the incumbent mobile operator while firm $B$ is a new entrant. Consumers face a switching cost $S \geq 0$ when changing from $A$ to $B$. Hence, $S$ reflects the consumers' valuation of keeping their telephone number. In addition, suppose that consumers are uniformly distributed between 0 and 1 . Finally, assume that for given income $y$, a consumer located at $x$ receives utility $U_{A}$ and $U_{B}$ when joining network $A$ or $B$, respectively, with

$$
\begin{aligned}
U_{A} & =y+v_{0}-\tau x+u(q), \\
U_{B} & =y+v_{0}-S-\tau(1-x)+u(q) .
\end{aligned}
$$

Here, $v_{0}$ denotes a consumer's intrinsic value of being connected to a mobile telephone network, and $\tau$ reflects the degree of network differentiation. The term $u(q)$ measures consumers' utility from making calls so that for a given call price $p$ consumers' indirect utility is given by $v(p) \equiv \max _{q}(u(q)-p q)$, i.e. we assume that consumers are indifferent 
to incoming calls. ${ }^{4}$

We consider the case where mobile operators $i=A, B$ compete in non-linear prices, i.e. they choose two-part tariffs consisting of a fixed subscription fee $F_{i}$ and variable service charges $p_{i j}$ for mobile services (such as calls, SMS, etc.) indexed by $j=1, \ldots, n$. Hence, mobile operator $i$ offers a tariff function

$$
W_{i}\left(q_{i 1}, \ldots, q_{i n}\right)=F_{i}+\sum_{j=1}^{n} p_{i j} q_{i j}, \quad i=A, B .
$$

It is well known that firms set service charges at marginal cost when they can set multipart tariffs, i.e. $p_{i j}=c_{i j} \cdot{ }^{5}$ For simplicity, we follow Wright (2002) and Gans and King (2000) in focusing our analysis on fixed-to-mobile calls, ignoring the more complex issue of mobile-to-mobile interconnection. ${ }^{6}$ We also assume that firms' marginal costs are constant and symmetric. Given these assumptions, the market share of mobile operator $A$ is given by

$$
s_{A}=\frac{1}{2}+\sigma S+\sigma\left(F_{B}-F_{A}\right),
$$

where $\sigma \equiv 1 /(2 \tau)$ is a measure of the substitutability of mobile networks, and $s_{B}=$ $1-s_{A}$. As is well known from the literature, an interior equilibrium exists only if $\sigma$ and $S$ are not too high. ${ }^{7}$

Regarding the fixed network, let us assume that consumers' indirect utility from calling people on their mobile network is given by the quadratic function $\varphi(p)=(a-$ $\left.b p_{F}\right)^{2} / 2$ where $p_{F}$ is the price for a fixed-to-mobile call. Hence, we obtain a linear demand function $q\left(p_{F}\right)=a-b p_{F}$ for fixed-to-mobile calls.

Finally, we assume that mobile networks set their termination charges $t_{i}$ for fixedto-mobile calls simultaneously. If the fixed network is able to set multi-part tariffs, the prices for fixed-to-mobile calls will be given by $p_{F i}=t_{i}$ for $i=A, B$. The marginal cost for terminating fixed-to-mobile calls is denoted by $c_{T}$ and assumed to be symmetric for the two mobile networks.

\footnotetext{
${ }^{4}$ Apart from the incorporation of switching costs, this is the basic set-up of virtually all network competition models as introduced by Laffont, Rey and Tirole (1998) and Armstrong (1998). It is also used in the literature referenced above, i.e. Aoki and Small (1999), Gans and King (2000) and Wright (2002).

${ }^{5}$ Intuitively, by setting service charges equal to marginal cost firms maximize the consumers' surplus that they can extract using the fixed fee (see, e.g., Laffont, Rey and Tirole, 1998).

${ }^{6}$ The analysis of mobile-to-mobile calls is more complex since changes in the relevant termination charges also affect the market shares of mobile networks.

${ }^{7}$ More specifically, we constrain our analysis to cases where $2 \sigma S \leq 3$. Otherwise $A$ would capture the entire market so that $B$ would not have entered the mobile market in the first place.
} 


\subsection{Competition without MNP}

In the absence of MNP, the incumbent mobile network $A$ typically has a competitive advantage, as consumers face switching costs $S \geq 0$ when switching to operator $B$. Furthermore, the customers of the fixed network can perfectly distinguish the mobile networks $i=A, B$ through their numbering prefixes. Hence, assuming a balanced calling pattern, network $i$ 's profit is given by

$$
\pi_{i}=s_{i} F_{i}+k s_{i}\left(t_{i}-c_{T}\right)\left(a-b t_{i}\right), \quad i=A, B .
$$

The first term reflects the profit generated by the subscription fee charged to $i$ 's customer base. The second term represents the profit from fixed-to-mobile calls terminated on network $i{ }^{8}$ Maximizing over $F_{i}$ and $t_{i}$ yields

$$
\begin{aligned}
t_{A} & =t_{B}=\frac{1}{2 b}\left(a+b c_{T}\right) \\
F_{A} & =\frac{1}{2 \sigma}-\frac{1}{4} \frac{k}{b}\left(a-b c_{T}\right)^{2}+\frac{1}{3} S, \\
F_{B} & =F_{A}-\frac{2}{3} S .
\end{aligned}
$$

Since both mobile operators have monopoly power over the calls that are being made to their customers, it is not surprising that both termination charges are set at the monopoly level (see (1)). ${ }^{9}$ However, as (2) and (3) indicate, the associated monopoly profit of $(k / 4 b)\left(a-b c_{T}\right)^{2}$ is entirely used to "subsidize" consumers' subscription fees. Nevertheless, the incumbent operator $A$ is able to charge a higher fixed fee than operator $B$, since $A$ can exploit its customer base facing switching costs. Put differently, operator $B$ has to offer a lower fixed fee to attract consumers. For later reference, note that equilibrium market shares are given by $s_{A}=(1 / 2)+(1 / 3) \sigma S$ and $s_{B}=(1 / 2)-(1 / 3) \sigma S$, and firms' profits are $\pi_{i}=s_{i}^{2} / \sigma$ for $i=A, B$.

\subsection{Competition with MNP}

As explained above, we model MNP as having two effects: First, MNP enhances competition between mobile networks. Second, with MNP in place, fixed network customers cannot determine ex ante which mobile network they are calling when placing a call to a particular number. ${ }^{10}$ More specifically, we make the following assumptions:

\footnotetext{
${ }^{8}$ Recall that all other service charges are set so as to equal marginal cost, i.e. the corresponding terms are equal to zero.

${ }^{9}$ Note that our analysis differs here from Gans and King (2000) and Wright (2002) as we assume that termination charges and subscription fees are set simultaneously, while Gans and King (2000) and Wright (2002) assume that subscription fees are chosen once the termination rates have been set.

${ }^{10}$ Equivalently, customers do not know ex ante the price of the service they wish to purchase.
} 
(A1) With MNP, consumers face no switching costs $(S=0)$.

(A2) With MNP, consumers base their calling decision on the average price for fixed-tomobile calls, i.e.

$$
\bar{p}_{F}=s_{A} t_{A}+s_{B} t_{B}
$$

Intuitively, (A1) requires that the introduction of MNP eliminates switching costs altogether. Assumption (A2), in turn, reflects the notion of consumer ignorance proposed by Gans and King (2000), which assumes that consumers base their calling decisions on the average price for fixed-to-mobile calls. These assumptions may be considered extreme, as in practice MNP will neither completely eliminate consumer switching costs, nor lead to complete consumer ignorance. Nevertheless, we think that they are useful in the present context, since they considerably simplify the analysis, but do not undermine the basic trade off under study (reduced switching costs v. reduced tariff transparency). ${ }^{11}$

Using (A1) and (A2), operator $i$ maximizes

$$
\pi_{i}=s_{i} F_{i}+k s_{i}\left(t_{i}-c_{T}\right)\left(a-b\left(s_{i} t_{i}+\left(1-s_{i}\right) t_{j}\right)\right), \quad \text { for } i, j=A, B \text { and } j \neq i .
$$

Maximizing over $F_{i}$ and $t_{i}$ now yields

$$
\begin{aligned}
t_{A}^{M N P} & =t_{B}^{M N P}=\frac{1}{3 b}\left(2 a+b c_{T}\right), \\
F_{A}^{M N P} & =F_{B}^{M N P}=\frac{1}{2 \sigma}-\frac{2}{9} \frac{k}{b}\left(a-b c_{T}\right)^{2} .
\end{aligned}
$$

Thus, the introduction of MNP removes the networks' asymmetry, so that mobile operators charge both the same termination and subscription fees and, accordingly, have the same market shares $s_{A}^{M N P}=s_{B}^{M N P}=1 / 2$.

It is important to note that both network operators increase their termination charges for fixed-to-mobile calls $\left(t_{i}^{M N P}>t_{i}\right.$, for $\left.i=A, B\right)$. This follows from the fact that operator $i$ does not bear the full consequences of increasing its termination charge $t_{i}$, since consumers base their calling decisions on the average price $\bar{p}_{F}$ rather than individual prices $t_{i}$. That is, operators exert a negative externality on each other when increasing their termination charges. Since this externality leads to termination charges above the monopoly level, the operators' profits from fixed-to-mobile termination decrease, and hence the "cross-subsidies" towards the fixed fee must also decrease.

Condition (5) further indicates that $F_{B}$ unambiguously increases with the introduction of MNP. With the asymmetry between networks removed, $B$ no longer has an

\footnotetext{
${ }^{11}$ In fact, while we overstate the potential cost of MNP that results from reduced tariff transparency, we also overplay its benefits as the switching cost may still be larger than zero in reality even with MNP.
} 
incentive to offer a discount (relative to $A$ ) so as to induce switching. In addition, the funds available for "cross-subsidization" are reduced, which reinforces the increase of $F_{B}$. The effect on the incumbent's subscription fee $F_{A}$ is less clear-cut. Both the "crosssubsidization" and the incumbency advantage are reduced, with ambiguous net effect on $F_{A} \cdot{ }^{12}$ Finally, note that firms' profits are still given by $\pi_{i}=s_{i}^{2} / \sigma$.

\subsection{Distributional and Welfare Effects of MNP}

In order to analyze the overall effects of MNP, we consider each of the groups affected: The mobile operators, $A$ and $B$, their respective customers, and the customers of the fixed network placing fixed-to-mobile calls. First, consider the effects of MNP on the profits of mobile operators. As indicated above, profit functions are given by $\pi_{i}=s_{i}^{2} / \sigma$ for $i=A, B$ both with and without MNP, i.e. mobile operators' profits are convex in own market shares. Since MNP aligns the mobile operators' market shares, it follows immediately that aggregate profits must decrease. That is, the extra profits awarded to $B$ are smaller than the profit reduction of $A$. In general, we should thus expect the incumbent $A$ [the competitor $B$, respectively] to oppose [support] the introduction of MNP, while aggregate industry profits decrease.

The customers of the fixed network are always adversely affected by the introduction of MNP. To see this, recall that mobile operators raise their fixed-to-mobile termination charges above the monopoly level $\left(t_{i}^{M N P}>t_{i}\right.$ for $\left.i=A, B\right)$ when MNP is introduced. Since the fixed network sets non-linear prices, the variable prices for fixed-to-mobile calls are set equal to marginal costs (i.e. the termination charges). The customers' indirect utility therefore decreases by $k\left(a-b c_{T}\right)^{2} / 8-k\left(a-b c_{T}\right)^{2} / 18>0$.

Finally, consider the effect of MNP on mobile customers. One might expect that mobile customers always benefit from MNP. After all, customers of network $B$ directly gain from the removal of switching costs, as their utility is no longer reduced by $S$. In addition, MNP implies that consumers' subscription decisions are no longer distorted by switching costs ${ }^{13}$ i.e. consumers' average "transport" costs decrease. However, the fixed fee for customers of network $B$ will generally increase, while $F_{A}$ may fall or raise, depending on parameter values. ${ }^{14}$ Hence, the overall effect of MNP on the consumers' surplus is ambiguous in general. More formally, in the absence of MNP, the surplus of

\footnotetext{
${ }^{12}$ More specifically, the introduction of MNP will strictly reduce $A$ 's fixed fee $\left(F_{A}^{M N P}<F_{A}\right)$ if the switching cost without MNP is sufficiently high, i.e. $S>\frac{1}{12} \frac{k}{b}\left(a-b c_{T}\right)^{2}$.

${ }^{13}$ Customers with a preference for network $B$ will no longer choose $A$ simply because of the existence of switching costs.

${ }^{14}$ The average subscription fee will strictly fall with the introduction of MNP iff $k<$ $8 b \sigma S^{2} /\left(a-b c_{T}\right)^{2}$.
} 
mobile customers' is given by

$$
\begin{aligned}
C S M & =y+v_{0}+u(q)-s_{A} F_{A}-\left(1-s_{A}\right)\left(F_{B}+S\right)-\tau\left(\int_{0}^{s_{A}} x d x+\int_{s_{A}}^{1}(1-x) d x\right) \\
& =y+v_{0}+u(q)-s_{A} F_{A}-\left(1-s_{A}\right)\left(F_{B}+S\right)-\frac{\tau}{2}\left(s_{A}^{2}+\left(1-s_{A}\right)^{2}\right) .
\end{aligned}
$$

With MNP (where $F_{A}^{M N P}=F_{B}^{M N P}$ and $S=0$ ) mobile consumers obtain the surplus

$$
C S M^{M N P}=y+v_{0}+u(q)-F_{A}^{M N P}-\frac{\tau}{4} .
$$

In equilibrium, mobile customers are thus strictly better off with MNP if

$$
\triangle C S M \equiv C S M^{M N P}-C S M=\frac{1}{2} S-\frac{1}{18} \sigma S^{2}-\frac{1}{36} \frac{k}{b}\left(a-b c_{T}\right)^{2}>0 .
$$

That is, the customers of mobile networks are less likely to benefit from MNP when mobile networks are close substitutes ( $\sigma$ is high) and the market for fixed line telephony is large ( $k$ is high), so that mobile operators dispose of sizeable funds from the fixed-tomobile monopolies to "cross-subsidize" subscription fees.

Alternatively, we may characterize the effects on mobile customers by referring to the various types of consumer benefits listed in Table 2. First, recall that benefits of type $1 \mathrm{~A}$ result from the avoided costs of number changes, i.e. they accrue to consumers who switch even in the absence of MNP. In our model, there are $\left(\frac{1}{2}-\frac{1}{3} \sigma S\right)$ consumers who switch to network $B$ even in the absence of MNP, so that the total switching costs saved with MNP amount to $\left(\frac{1}{2}-\frac{1}{3} \sigma S\right) S$. Second, benefits of type $1 \mathrm{~B}$ - those associated with moving to a new operator - accrue to consumers who only switch with MNP (but not without MNP). In our model, these customers save the "transport" costs $\frac{1}{18} \sigma S^{2}$ of subscribing to the less preferred network, once MNP is implemented, i.e. these customers save the "transport" costs of being connected to the less liked network. Third, benefits of type 2 associated with more intense competition result from changes in the fixed fees that mobile consumers have to pay. More formally, type 2 benefits total

$$
s_{A} F_{A}+\left(1-s_{A}\right) F_{B}-F_{A}^{M N P}=\frac{2}{9} \sigma S^{2}-\frac{1}{36} \frac{k}{b}\left(a-b c_{T}\right)^{2} .
$$

As is easily verified, the sum of the benefits of type $1 \mathrm{~A}, 1 \mathrm{~B}$ and 2 is equivalent to $\triangle C S M$.

Next, let us examine the total welfare effect of MNP. Suppose that there is an exogenous investment cost $I$ associated with the implementation of MNP. Let $W^{M N P}$ and $W$ denote total welfare with and without MNP, respectively. Then, introducing MNP increases welfare if $\Delta W \equiv W^{M N P}-W \geq 0$. Alternatively, let $I^{*}$ denote the critical level of investment costs below which the introduction of MNP is desirable from a welfare point of view, i.e. $\Delta W \geq 0$ for $I \leq I^{*}$. In equilibrium, $I^{*}$ is given by

$$
I^{*}=\frac{1}{2} S-\frac{2}{9} \sigma^{2} S^{2}-\frac{1}{18} \sigma S^{2}-\frac{k}{72}\left(5+\frac{2}{b}\right)\left(a-b c_{T}\right)^{2} .
$$


Straightforward calculations show that $\partial I^{*} / \partial \sigma<0$ and $\partial I^{*} / \partial k<0$. That is, the introduction of MNP is less likely to bring about welfare gains if the mobile networks are close substitutes and the market for fixed line telephony is large.

Intuitively, if mobile networks are close substitutes ( $\sigma$ is high) and competition is thus intense, introducing MNP does not strongly affect the consumers' subscription decisions. That is, the benefits of introducing MNP are relatively small. The costs of introducing MNP, however, persist even if mobile networks are close substitutes, since consumers still base their calling decisions on average prices; mobile operators therefore have an incentive to increase their termination charges. Because mobile operators directly determine the prices that the fixed network customers pay for fixed-to-mobile calls, the main effect of MNP is to increase the prices of the fixed network. Clearly, this adverse effect is more pronounced if the market for fixed line telephony is large ( $k$ is high).

\section{Extensions}

We now consider three extensions of our model: First, we study the introduction of MNP using a "call-forwarding" solution, which typically involves lower investment costs, but also leads to an increase in conveyance costs (see, e.g., Oftel, 1997). Second, we examine how the results of our above analysis are affected if mobile termination charges are regulated, so that mobile operators cannot exploit consumer ignorance by increasing termination charges. Finally, we examine whether alternative carrier identification mechanisms may solve the consumer ignorance problem.

\subsection{Call-forwarding Solutions}

So far, we have implicitly assumed that MNP is introduced using an Intelligent Network (IN) solution that only involves investments costs $I$, while the call carriage costs are the same as without MNP. If, however, MNP is implemented by "call-forwarding" rather than an IN solution, the assumption of constant conveyance costs is no longer realistic: Solutions based on call-forwarding typically lead to an increase in conveyance costs, as calls are routed relatively inefficient over the network (see, e.g., Oftel, 1997, Ovum, 2000). At the same time, the fixed costs associated with call-forwarding are typically smaller than those of an IN solution. To account for the possibility of implementing MNP by call-forwarding, let us assume that the marginal call termination cost increases to $c_{T}^{C F}>c_{T}$ under call-forwarding, and that the fixed investment cost is reduced to $I^{C F}<I$ (where the superscript $C F$ denotes call-forwarding). As a consequence, the 
mobile networks' tariff structure changes to

$$
\begin{aligned}
t_{A}^{C F} & =t_{B}^{C F}=\frac{1}{3 b}\left(2 a+b c_{T}^{C F}\right), \\
F_{A}^{C F} & =F_{B}^{C F}=\frac{1}{2 \sigma}-\frac{2}{9} \frac{k}{b}\left(a-b c_{T}^{C F}\right)^{2} .
\end{aligned}
$$

Given $c_{T}^{C F}>c_{T}$, this implies that termination charges increase (due to the cost increase), which leads to a fall in demand for fixed-to-mobile calls and, accordingly, in the total profit generated from these calls. This, in turn, implies that there is less money available to subsidize mobile customers' subscription fees, so that $F$ increases. As a result, mobile customers' surplus is clearly higher under an IN solution than under call-forwarding. Comparing $C S M^{M N P}$ and $C S M^{C F}$, we find that

$$
C S M^{M N P}-C S M^{C F}=\frac{2}{9} k\left(c_{T}^{C F}-c_{T}\right)\left(2 a-b\left(c_{T}^{C F}-c_{T}\right)\right)>0 .
$$

That is, mobile consumers are worse off with call-forwarding, as the increase in marginal termination costs indirectly leads to an increase in mobile subscription charges. Furthermore, fixed network customers also lose, as termination rates for fixed-to-mobile calls increase.

In terms of overall welfare, the picture is less clear, since the investment costs of a call-forwarding solution are lower. Let $\Delta I \equiv I-I^{C F}$ denote the additional investment costs to move from call-forwarding to an IN solution for implementing MNP. We can then find a critical difference in investment costs, $\Delta I^{*}$, such that $W^{M N P}>W^{C F}$ for $\Delta I<\Delta I^{*}$ where

$$
\Delta I^{*} \equiv \frac{2}{9} \frac{k}{b}\left[\left(a-b c_{T}\right)^{2}-\left(a-b c_{T}^{C F}\right)^{2}\right]+\frac{k}{18}\left[\left(a-b c_{T}\right)^{2}-\left(a-b c_{T}^{C F}\right)^{2}\right] .
$$

Hence, the additional fixed cost associated with an IN solution for MNP may be the larger, the larger the increase in conveyance costs associated with call-forwarding, and the larger the fixed-to-mobile market $(k)$ who suffers from this cost increase. If, however, the fixed cost exceeds the critical level $\Delta I^{*}$, implementing MNP via call-forwarding is welfare-superior to full MNP.

\subsection{Regulated Termination Charges}

We have pointed out above that introducing MNP is likely to induce mobile network operators to increase their termination charges. It it is therefore interesting to study how regulations of termination charges - which are already in place in a number of countries, at least for some of the firms - relate to the effects of introducing MNP. Let us therefore consider a very simple regulatory regime where the firms' termination charges 
must satisfy the condition $t_{i}=t_{i}^{M N P} \equiv t^{R}$, with the superscript $R$ indicating regulated termination charges. Provided that the regulatory regime remains unchanged with MNP, the latter has no effects on termination rates. In this case, fixed network customers are not affected by the introduction of MNP, as the charges for fixed-to-mobile calls also remain constant. While the subscriber charges for mobile customers, $F_{A}$ and $F_{B}$ are likely to increase with the regulation of termination charges (at least as long a the regulated charge is below the monopoly level), the case for introducing MNP becomes stronger with regulated termination fees. Calculating the change in mobile consumers' surplus resulting from the introduction of MNP, we now find that

$$
\Delta C S M=\frac{1}{2} S-\frac{1}{18} \sigma S^{2}
$$

Given our assumption that both $A$ and $B$ are active in the market for mobile services $(2 \sigma S \leq 3),{ }^{15}$ this implies that mobile consumers unambiguously benefit from MNP if termination rates are regulated. It is straightforward to show that under these circumstances, introducing MNP clearly improves overall welfare provided that investment costs $I$ associated with MNP are not too high. ${ }^{16}$

Summing up, while we do not wish to argue the case of mobile termination regulation in this paper, our analysis shows that it may be beneficial to complement the introduction of MNP with mobile termination regulation so as to avoid an increase in termination charges generated by reduced tariff transparency.

\subsection{Alternative Means of Carrier Identification}

Finally, let us reconsider the assumption that MNP will inevitably increase consumer ignorance. While we have already pointed out that this is not necessarily the case for countries where carriers cannot be identified via numbering prefixes even before introducing MNP, there may also be alternative means to inform consumers about the network to be called. In Finland, for example, consumers can call a toll-free enquiry number to learn about users' network association. In Portugal consumers are alerted by an acoustic signal when they place an off-net call. However, such mechanisms usually generate costs on their own, and they are often considered a nuisance by at least a subset of consumers. ${ }^{17}$

\footnotetext{
${ }^{15}$ See fn. 7 .

${ }^{16}$ More specifically, given that the industry's profits are reduced by $\frac{2}{9} \sigma^{2} S^{2}$, MNP is welfare enhancing if $I<\frac{1}{2} S-\frac{1}{18} \sigma S^{2}-\frac{2}{9} \sigma^{2} S^{2}$.

${ }^{17}$ In fact, Finland introduced an acoustic signal to identify networks when MNP was implemented in 2003. However, since many consumers complained as they found the mechanism annoying, the tone signal was later removed.
} 
In terms of our model, the nuisance of having to rely on alternative information devices may be modelled as reducing the utility of making mobile calls. More specifically, suppose that with the nuisance resulting from carrier identification $(C I)$, initial demand is reduced by a parameter $d$, which reflects this "disutility", i.e. $q^{C I}\left(p_{F}\right)=a-d-b p_{F}$. If, however, carrier identification can resolve the problem of consumer ignorance, mobile networks' optimal termination rates are given by $t_{A}^{C I}=t_{B}^{C I}=\left(a-d+b c_{T}\right) /(2 b)$. Hence, fixed network customers benefit from an alternative carrier identification methodology, compared to implementing MNP without carrier identification, if $k\left(a-d-b c_{T}\right)^{2} / 8-$ $k\left(a-b c_{T}\right)^{2} / 18>0$, or $\left(a-b c_{T}\right) / 3>d$. That is, the nuisance associated with an alternative carrier identification mechanism must be sufficiently small so as not to outweigh the benefits of overcoming the problem of consumer ignorance.

Similarly, mobile consumers benefit from a carrier identification mechanism, compared to implementing MNP without carrier identification, if $C S M^{M N P}<C S M^{C I}$ or $F_{i}^{M N P}>F_{i}^{C I}$ with $F_{i}^{C I}=\frac{1}{2 \sigma}-\frac{1}{4} \frac{k}{b}\left(a-d-b c_{T}\right)^{2}$. Again, this condition is satisfied it the nuisance is not too large, i.e. $d<\left(1-\frac{2}{3} \sqrt{2}\right)\left(a-b c_{T}\right)$.

Finally, in order to generate positive overall welfare effects, the additional fixed cost $I^{C I}$ of implementing an alternative carrier identification mechanism must not be larger than the benefits of reduced consumer ignorance, i.e.

$$
I^{C I} \leq \frac{k}{8}\left(a-d-b c_{T}\right)^{2}-\frac{k}{18}\left(a-b c_{T}\right)^{2}+\frac{1}{4} \frac{k}{b}\left(a-d-b c_{T}\right)^{2}-\frac{2}{9} \frac{k}{b}\left(a-b c_{T}\right)^{2} .
$$

\section{Conclusion}

In this paper, we have argued that the introduction of MNP generates various competitive effects that are of potential interest to regulatory authorities. In particular, we have provided an analytical framework for studying the economic costs associated with a reduction in tariff transparency that may result if the prefix of a mobile telephone number no longer indicates its network assignment - an aspect that was largely ignored in previous studies on MNP. Furthermore, we have shown that introducing MNP may have subtle price effects: While the incumbent may lower its fixed subscription fee, the entrant may actually increase it, as it does not have to compete as fiercely for customers as without MNP. Finally, we have shown that depending on the set-up costs, the overall welfare effect of introducing MNP is generally ambiguous.

The introduction of mandatory MNP should be expected to divide providers of mobile services into supporters and opponents: While the new mobile operator benefits, the incumbent will typically lose. Therefore, effects on mobile customers will also be ambiguous. In addition, customers of the fixed network are likely to be adversely affected due to higher termination charges for fixed-to-mobile calls. 
These adverse effects of reduced tariff transparency may be alleviated if either termination charges are regulated or if there are relatively inexpensive alternative means of carrier identification. In fact, MNP and the regulation of mobile termination charges may be complementary from a regulatory perspective: With regulated termination charges, MNP is more likely to be welfare enhancing than without. Conversely, with MNP the case for the regulation of mobile termination charges is stronger than without MNP.

We believe that these findings might be helpful for regulatory authorities debating the introduction of mandatory MNP. One should keep in mind, however, that we have adopted the simplest version of the standard network competition model to explore the competitive effects of introducing MNP. In particular, we have abstracted from the challenging issue of mobile-to-mobile calls and ignored the possibility of further entry into mobile telecommunications markets. Future research into these directions might prove to be instructive for theorists and practitioners alike.

\section{References}

Aoki, R. and J. Small (1999), The economics of number portability: Switching costs and two-part tariffs, working paper, University of Auckland, November 1999.

Armstrong, M. (1998), Network interconnection in telecommunications, Economic Journal 108, 545-564.

European Commission (2002), Eighth Report from the Commission on the Implementation of the Telecommunications Regulatory Package, COM(2002) 695, Brussels: December 2002.

Gans, J.S. and S.P. King (2000), Mobile network competition, customer ignorance and fixed-to-mobile call prices, Information Economics and Policy 12, 301-327.

Gans, J.S., King, S.P. and G. Woodbridge (2001), Numbers to the people: Regulation, ownership, and local number portability, Information Economics and Policy 13, 167-180.

Haucap, J. (2003), Telephone number allocation: A property rights approach, European Journal of Law and Economics 15, 91-109.

INTUG (2003), Mobile Number Portability, International Telecommunications User Group (INTUG): [www.intug.net/mnp].

Laffont, J.J., Rey, P. and J. Tirole (1998), Network competition I: Overview and nondiscriminatory pricing, RAND Journal of Econmics 29, 1-37. 
Laffont, J.J. and J. Tirole (2000), Competition in Telecommunications, MIT Press: Cambridge, MA.

NERA/Smith (1998), Feasibility Study \& Cost Benefit Analysis of Number Portability for Mobile Services in Hong Kong, Final Report to OFTA, NERA/Smith: London, May 1998.

Oftel (1997), Economic Evaluation of Number Portability in the UK Mobile Telephony Market, Oftel: London, July 1997.

Ovum (2000), Mobile Numbering and Number Portability in Ireland, A Report to the ODTR, Ovum: London, October 2000.

Reinke, T.H. (1998), Local number portability and local loop competition, Telecommunications Policy 22 (1), 73-87.

Schwarz-Schilling, C. and U. Stumpf (1999), Netzbetreiberportabilität im Mobilfunkmarkt: Auswirkungen auf Wettbewerb und Verbraucherinteressen, Discussion Paper No. 199, WIK: Bad Honnef, December 1999.

Wright, J. (2002), Access pricing under competition: An application to cellular networks, Journal of Industrial Economics 50, 289-315. 
Working Papers of the Socioeconomic Institute at the University of Zurich

The Working Papers of the Socioeconomic Institute can be downloaded from http://www.soi.unizh.ch/research/wp/index2.html

$0303 \quad$ Mobile Number Portability

Stefan Buehler and Justus Haucap, 2003, 19 p.

0302 Multiple Losses, Ex-Ante Moral Hazard, and the Non-Optimality of the Standard Insurance Contract

Michael Breuer, 2003, 18 p.

$0301 \quad$ Lobbying against Environmental Regulation vs. Lobbying for Loopholes Andreas Polk and Armin Schmutzler, 2003, 37 p.

$0214 \quad$ A Product Market Theory of Worker Training Hans Gersbach and Armin Schmutzler, 2002, 34 p.

0213 Weddings with Uncertain Prospects - Mergers under Asymmetric Information Thomas Borek, Stefan Buehler and Armin Schmutzler, 2002, 37 p.

$0212 \quad$ Estimating Vertical Foreclosure in U.S. Gasoline Supply Zava Aydemir and Stefan Buehler, 2002, 42 p.

$0211 \quad H o w$ much Internalization of Nuclear RiskThrough Liability Insurance? Yves Schneider and Peter Zweifel, 2002, 18 p.

$0210 \quad$ Health Care Reform and the Number of Doctor Visits ? An Econometric Analysis Rainer Winkelmann, 2002, 32p.

0209 Infrastructure Quality in Deregulated Industries: Is there an Underinvestment Problem?

Stefan Buehler, Armin Schmutzler and Men-Andri Benz, 2002, 24 p.

0208 Acquisitions versus Entry: The Evolution of Concentration Zava Aydemir and Armin Schmutzler, 2002, 35 p.

0207 Subjektive Daten in der empirischen Wirtschaftsforschung: Probleme und Perspektiven.

Rainer Winkelmann, 2002, 25 p.

$0206 \quad$ How Special Interests Shape Policy - A Survey Andreas Polk, 2002, 63 p.

$0205 \quad$ Lobbying Activities of Multinational Firms Andreas Polk, 2002, 32 p.

0204 Subjective Well-being and the Family Rainer Winkelmann, 2002, 18 p.

$0203 \quad$ Work and health in Switzerland: Immigrants and Natives Rainer Winkelmann, 2002, 27 p.

0202 Why do firms recruit internationally? Results from the IZA International Employer Survey 2000 Rainer Winkelmann, 2002, 25 p.

0201 Multilateral Agreement On Investments (MAI) - A Critical Assessment From An Industrial Economics Point Of View Andreas Polk, 2002, 25 p. 